\title{
Design of Environmental Protection System in the Construction of New Economic Zone in China
}

\author{
Yongbin Zhao \\ College of Political Science and Law of Yulin University, Yulin, Shaanxi, 719000
}

Keywords: Environmental Protection, New Economic Zone Construction, System Design Progress, Control Charts, Process Capability

\begin{abstract}
The environmental protection system in the economic zone is an important issue in the construction of recycling economy. The construction of the system is its foundation. How to design an effective environmental protection system, standardize the circular economy in the national system, marketization in operation, and practice it in enterprises has become an important issue that theorists should pay attention to in the fields of theory and practice. Developing circular economy is a major strategic measure to prevent and control pollution and protect the environment by implementing the strategy of resources, promoting the sustainable use of resources and safeguarding the economic security of the country. It is also an important way to tackle the challenges posed by China's accession to the WTO, promote the transformation of economic growth mode and enhance the competitiveness of enterprises. Ways and objective requirements. This article has carried on the preliminary exploration and the research to the construction of the environmental protection system in the economic zone.
\end{abstract}

\section{Introduction}

International experience shows that in order to smoothly promote the development of circular economy, we must have a sound system as a guarantee. Therefore, we must speed up the legislative process of recycling economy and build a supporting environmental protection system for recycling economy, which is an important reality for promoting the smooth development of recycling economy. At present, there are some problems in our country, such as the existing regulations and policies, imperfect policies, imperfect systems and mechanisms, Meaning and theoretical significance. Innovation not only refers to technological innovation, but also includes promoting institutional innovation so that all creation that is conducive to social progress can be brought into play. To vigorously develop circular economy in our country, we must innovate the legal system of environmental protection through government, enterprises and consumers, supplement the market system and enterprise system, and use the economic stimulus system such as taxes and incentives to strengthen publicity to the public Education so that the entire people can work together to save the limited resources, solve the increasingly serious environmental problems and realize the sustainable development of humankind today, with the deepening contradictions between the environment and the economy and society.

\section{Analysis on the Development of Insurance System}

Since the reform and opening up, our government has introduced the restraint and incentive measures in terms of laws, regulations, policies, standards and so on, establishing a policy system conducive to resource conservation and environmental protection, creating a system environment for the development of circular economy and constantly improving laws and regulations, But still in its initial stage of development in the national system. Specific laws and regulations on circular economy are under study and formulated.

China's first circular economy in the field of laws and regulations, "Guiyang City, circular economy eco-city construction Ordinance" has been officially promulgated by the Standing Committee of Guiyang City, and the date of implementation. The promulgation and implementation 
of this Ordinance will help regulate the behavior of the government, enterprises and the public in advancing the economic zone and provide legal protection for the construction of an ecologically-friendly city with a circular economy. The promulgation of circular economy regulations in Guiyang shows that the new model commonly adopted by the developed countries in this world began to be implemented in our country. In addition, the National Development and Reform Commission promulgated the "energy-saving special plan," put forward the recent ten major energy-saving projects. The Cleaner Production Audit Regulations and the China Water Conservation Technical Program have been promulgated one after another and various local laws and regulations have been promulgated. By the year cities such as Shaanxi, Liaoning, Jiangsu and Shenyang, Taiyuan and other cities have formulated local cleaner production policies And regulations.

At present, China has not issued a special law of circular economy, is still planning stage. In the years, the NPC Standing Committee decided to readjust its legislative plan and incorporate the Circular Economy Law. With all efforts, there is now a preliminary outline of the draft law, including the administrative coercive measures, economic incentives, the obligations and responsibilities of the government and relevant parties that are needed to support the development of circular economy. According to the People's Daily reported that the Circular Economy Law is expected to be submitted to the Standing Committee of the National People's Congress for consideration next month. At the same time as the law came into force, a number of supporting laws and regulations will be promulgated and implemented simultaneously.

At present, China's development of circular economy laws and regulations lag, or lack of maneuverability. Although some relevant laws and regulations have been promulgated in our country, many gaps still exist. The construction of laws and regulations on the recycling of renewable resources is still the weak link, and the circular economy legislation is still under discussion. China's development of circular economy, legislation should be the first move to improve the promotion of circular economy laws and regulations system is to establish a recycling economy, an important means of security system. The choice of legislative mode in our country, as far as China's current legislation is concerned, is still in the stage of anti-fouling at source and has not yet reached the stage of full circulation of economic operation. Therefore, it belongs to the model of pollution prevention legislation. However, by its nature, our country has formed an independent clean production legislation based on the Environmental Protection Law. It is more similar to the legislative systems of Germany and Japan and is also easier to develop and establish a cycle after the conditions in the society and the legal system are ripe. Economic legal system.

Publicity and education means that managers use publicity and education institutions to promote public awareness of circular economy by means of publicity and education so that they can participate in the development of recycling economy consciously. Educational means and economic means have very good complementarity, and have great advantages in terms of universality and continuity. Foreign studies show that the deeper the public understanding of the policy of circular economy, the deeper their own participation and support policies, the better the effect of policy implementation. International experience shows that building a conservation-oriented society requires the participation of the entire society and requires an overall improvement in the quality of the people. This requires long-term publicity, education and policy promotion.

At the social level, it is mainly the formation of a social atmosphere for the development of a recycling economy that makes recycling of resources a voluntary act of the public. By strengthening the disclosure of environmental information, consumers are provided with more information to choose from to combat environmentally harmful products and services and to use products and services that are good for the urban environment. An important way to encourage direct public participation is to include public hearings in the environmental assessment of major urban projects. This approach can increase public awareness of environmental issues and develop and leverage the role of intermediary organizations.

At the government level, there are mainly policy support and institutional constraints, and the government should play a role in areas where businesses and the society can not function effectively. 
We will formulate various encouragement policies for the development of circular economy, speed up the pilot projects and demonstrations at all levels of the circular economy, build a technology platform and step up media publicity so as to create a good atmosphere for resource conservation in the whole society.

\section{Three-Dimensional Environmental Protection System Planning and Design}

Sustainable development refers to the coordinated development of economy, society, resources and environmental protection. They are an inseparable system. They must not only achieve the goal of economic development but also protect the natural resources and environment upon which mankind depends and enable future generations to Sustainable development and live and work in peace. Environmental protection is an important aspect of sustainable development. The core of sustainable development is development. However, it requires the economic and social development under strict control of population, improvement of population quality, protection of the environment and sustainable use of resources. Sustainable development is based on economic growth, is based on the protection of nature, coordinates with the carrying capacity of resources and the environment, and aims at improving and improving people's quality of life in harmony with social progress. The purpose of circular economy is to achieve sustainable development, so to establish a recycling economy and environmental protection system must be based on sustainable development as its fundamental guiding principle.

Cleaner production requires implementing the principle of pollution prevention throughout the entire production cycle, reducing resource consumption from the source of production, developing recyclable resources, and curbing pollution production so as to achieve a win-win result of pollution and environmental benefits. Recycling economy advocates environmental friendliness, advocating that in the process of product and consumption, with minimal input of natural resources to get the most product output, while emitting as little as possible environmental waste to reduce and avoid the harm to the environment. Circular economy provides an ideal mode of economic development for sustainable development and finds a reasonable balance between the contradictions and conflicts between environment and development.

In promoting the development of circular economy, we must pay attention to giving full play to the market in the allocation of resources in the basic role of the government's leading role in the main role of enterprises to promote the overall formation of circular economy together for building a resource-saving and environment-friendly society Provide institutional and institutional safeguards. The national system refers to the regulation and control of the macroeconomic level in the country. It plays an instructive role in both the market system in macro view and the micro-enterprise system. However, the micro-enterprise system also needs some market systems to guide, the market system and There is a cross between the enterprise system. The system design of circular economy must emphasize the maneuverability of the legal system, implement the principle of "reduction, reuse and resource", and pay attention to the actual effect of the system.

Pollution import control includes macro government subsidies and tax system China's original and highly operable "three simultaneous" system The state's industrial access system, planned responsibility system and the environmental impact assessment system based on prevention are Market system of resources, price system and environmental resources property rights system. Export control of pollution includes the system of trading of emission rights in the market system. The system of charging sewage charges includes a list of seized pollutants in the enterprise system, an on-site inspection system, a deadline management system, an eco-labeling system for product stages, a certification system for environmental management signs, Material handling stage of the monitoring system and certification system. The cleaner production system for the process control in the enterprise system, to expand the responsibility of the producer and the discharge of the principle of enterprise-wide system of control system. The market system includes the pricing system of resource in entrance control, the system of property rights of environmental resources and the trading system of emission rights in export control, and the system of charging for sewage.

The development of circular economy in China mainly formed a tripartite linkage mechanism of 
government, markets and enterprises and formed the pattern of promoting the development of circular economy in the whole society. To build a recycling economy and environmental protection system in China, we must take the sustainable development of the whole society as the ultimate goal, take the principle of cleaner production as the guidance of process management and the principle of recycling economy as the principle of construction, and establish an environmental protection system that suits China's national conditions. This chapter constructs and studies the environmental protection system from two aspects. The first is to establish a three-dimensional environmental protection system in China from a three-dimensional perspective of state system, market system and enterprise system. The second is to establish an environmental protection system from the perspective of pollution import and export control. Both of these angles follow the basic principles of system construction and strive to make the system clear and feasible.

In the implementation process of the planning system, the five mechanisms of information, decision-making, funding, supervision and accountability play a binding and stimulating role. Among them, the information mechanism is the core. Information is not only the basis for decision-making and fund allocation, but also the means for supervision and accountability . Information makes the decision-making more scientific, makes the fund distribution more reasonable, and makes supervision and accountability more effective. Information provides the basis for decision-making and formulates detailed fund allocation plans, division of responsibilities and measures. All these decision-making information, in turn, serves as a means of supervision and accountability through evaluation and rewards and punishments through information disclosure and public opinion supervision. These five mechanisms are interlocking and provide incentive compatibility from both the restraint and the incentive perspectives. The focal point of the information mechanism is to break the barriers of information communication between the current departments and establish a multi-agent, multi-channel and all-around information sharing platform. The design of the decision mechanism focuses on the establishment of a comprehensive top-down and bottom-up decision Platform, the formation of a wide range of stakeholder involvement, the full demonstration of those who implement, generally accepted by the implementation of the planning goal setting model; funding mechanism needs to be fully demonstrated in the process of a clear funding allocation plan; in planning and supervision, planning and implementation of performance evaluation should be Three-dimensional, the daily supervision and random checks combined. The lack of follow-up oversight and accountability in the planning process amounts to a dead letter, so the accountability mechanism is of crucial importance.

\section{Conclusion}

According to the relevant theory, in order to ensure the reality of the planning system and maneuverability. It is gratifying to note that during the 12th Five-Year Plan period, there will be more progress in the institutionalization of the plan. There are many institutional and institutional innovations such as regional defense and zone management and the division of a number of small watersheds into control units. Ecological compensation methods. Incentives are also more diversified. They will make comprehensive use of administrative and market measures, such as launching environmental taxes on river basin water pollution and implementing environmental insurance. In the overall planning, more attention should be paid to the study of environmental capacity and the evaluation of environmental carrying capacity. Based on this, structural adjustment, optimization and upgrading, and transformation of economic development mode should be adopted to achieve the coordinated, sustainable development of environment, society and economy. It can be predicted that the "12th Five-Year Plan" will be more standardized, more scientific and rational, give full play to the role of restraint and guidance, and promote environmental optimization and economic development.

\section{References}

[1] Liu Huiqin, Wang Haihong, Xie Yongyong. Practice and discussion on water environment 
protection in Xinning Industrial Park of Ningxia-Moutain Region of the Yellow River [J]. Inner Mongolia Water Resources. 2017 (08)

[2] Relaxation efforts to improve the level of water environmental protection in Jiangsu [J]. Mass. 2017 (17)

[3] Liu Juan. Research on water resources utilization and water environment protection in China [J]. Building Materials and Decoration. 2017 (43)

[4] Chongyang Pipeline Project to cut off urban sewage out of urban water environment protection [J]. Water Supply and Drainage Dynamics. 2013 (05)

[5] Tao Kun. Recommendations for Enhancing Protection of Water Environment in Ma'anshan City [J]. Jiangdong Forum. 2016 (04)

[6] Zhang Sanping. Wuhan water environment protection and eco-city construction [J]. Wuhan Construction. 2007 (02) 